\title{
Preface
}

\section{International Conference on Structural Engineering Dynamics - ICEDyn 2011}

The last edition of the International Conference on Structural Engineering Dynamics, ICEDyn 2011, took place in Tavira, Algarve, south coast of Portugal, on the $20^{\text {th }}-22^{\text {nd }}$ of June 2011, organized by the Instituto Superior Técnico (IST), from the Technical University of Lisbon, and the Instituto de Engenharia Mecânica (IDMEC). Although it has had previous editions, it was in 2007 that it became a biennial scientific event that has grown not only in quantity, but also in quality. Its highly rated Scientific Committee is a guaranty of excellence that attracts many reputed scientists from all over the world, representatives of the industrial community and young PhD students, interacting and sharing their expertise and experience during the event.

In this last edition we had the highest participation ever, with delegates from 19 countries, presenting 93 papers. From these, 46 papers have been submitted to this special issue, which has been carefully prepared. After a tough reviewing process, where most of the papers have been scrutinized by three reviewers, 12 have been rejected and 34 have been approved. These papers cover a wide spectrum of subjects that include modal updating, non-linear dynamics, damage detection, modeling of damping, etc., and reflect the excellent outcome of ICEDyn 2011.

It was a pleasure and an honor to have served as Guest Editors of Shock and Vibration.

Acknowledgements are due to all the authors and co-authors, to the reviewers for all their time and collaboration, to the Publication Manager Rasjel van der Holst, and to both past and present SAV Editors-in-Chief, Profs. Daniel Inman and Mehdi Ahmadian, respectively, for their interest and enthusiasm in supporting this special issue.

Nuno M. M. Maia

Miguel M. Neves

Guest Editors

Instituto Superior Técnico

Dept. Eng ${ }^{a}$ Mecânica

Av. Rovisco Pais,

1049-001 Lisbon

Portugal 

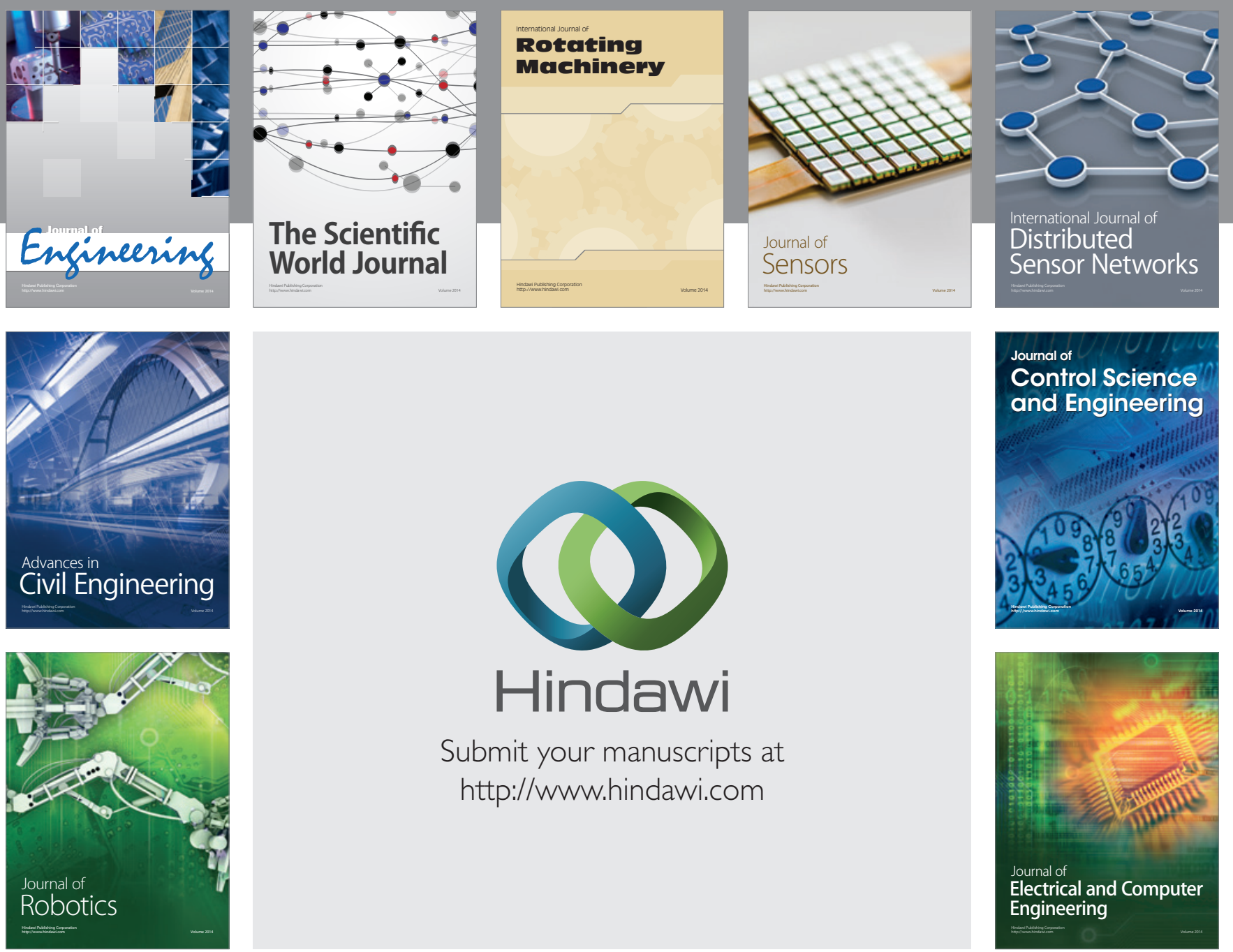

Submit your manuscripts at

http://www.hindawi.com
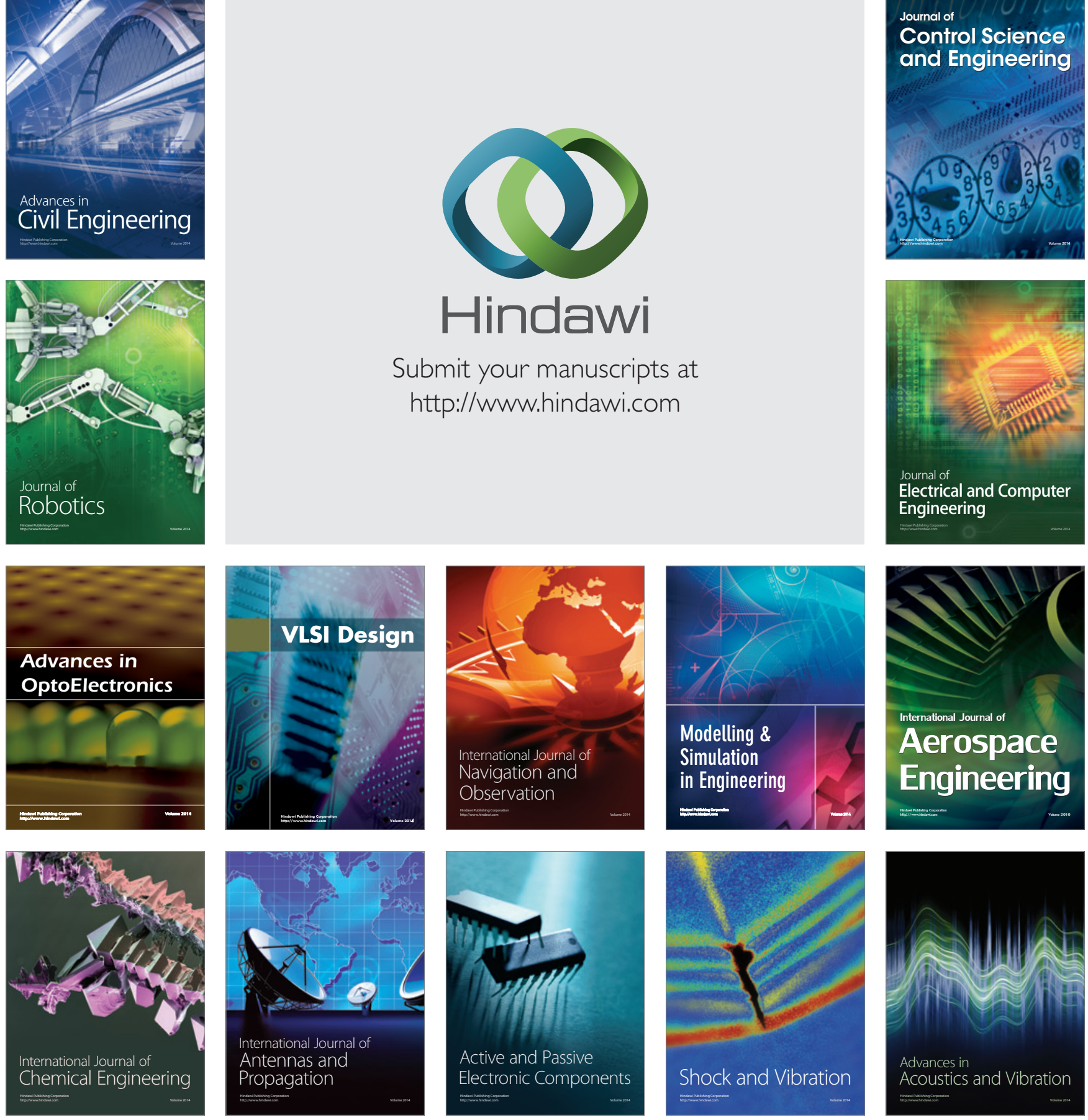